\title{
A POLÍTICA DE COMBATE À POBREZA DO GOVERNO DO ESTADO DE SÃO PAULO
}

Maria Helena Guimarães de Castro

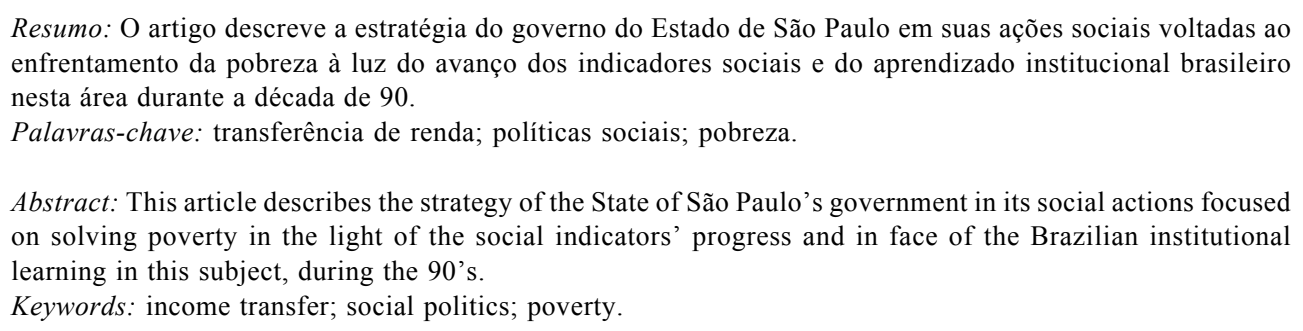

$\mathrm{O}$ Estado de São Paulo já alcançou níveis de desenvolvimento econômico e social bem acima da média nacional, equiparando-se aos demonstrados pelos países mais desenvolvidos da América Latina. Isso ainda é pouco e seria bom se a situação do Brasil se igualasse à de países como Espanha e Portugal. Entretanto, há ainda um bom caminho a percorrer em direção ao progresso social efetivo.

É esse o objetivo da área social do governo do Estado de São Paulo: uma concepção de política social voltada para o desenvolvimento humano. As ações para enfrentar as situações de pobreza extrema e exclusão social inscrevem-se em uma proposta mais ampla de promoção do bemestar social a todos os cidadãos. Ações baseadas nessa premissa supõem e contribuem para promover um novo relacionamento entre Estado democrático e sociedade, alicerçado na participação dos cidadãos e de suas comunidades e organizações, nas parcerias entre diferentes atores públicos e privados, na descentralização e na convergência e articulação das ações da administração estadual e destas com as iniciativas de outros níveis de governo.
Nas sociedades democráticas contemporâneas, a garantia de condições mínimas de bem-estar para toda a população depende de três conjuntos de ações governamentais: as políticas capazes de assegurar o crescimento econômico sustentado com expansão do trabalho, do emprego e da renda; as políticas sociais universais destinadas a promover a igualdade de oportunidades e padrões básicos de qualidade de vida, como a educação e a saúde; e as políticas sociais focadas em grupos mais vulneráveis ou vítimas de discriminação ou exclusão social.

Pobreza e desigualdade são os grandes desafios da sociedade brasileira no século XXI, cujas raízes remontam ao passado histórico, mas suas causas mais imediatas encontram-se nas limitações do processo de desenvolvimento conduzido pelo Estado; na crise fiscal do Estado a partir da década de 80 e nas conseqüências do processo de reestruturação econômica imposto pela globalização.

Dotar o país de um sistema eficiente e democrático de proteção social é tarefa complexa e difícil e não se esgota nas responsabilidades - fundamentais - do governo e não se cumpre de uma hora para outra. Exige a ação responsá- 
vel dos três poderes da República, o envolvimento dos diversos níveis de governo, a participação ativa e responsável da sociedade civil e de suas organizações, a colaboração de empresas, universidades, igrejas e sindicatos. Sobretudo, não é tarefa de um governo, mas de todos.

Os anos 90 foram de grandes avanços nas políticas sociais, seja do ponto de vista da sua institucionalização e fontes de financiamento, seja do ponto de vista da eficiência e resultados. Todas as recentes publicações do Instituto Brasileiro de Geografia e Estatística - IBGE de síntese de indicadores sobre as condições sociais da população, entre 1992 e 2002, comprovam essa afirmação. $\mathrm{O}$ mesmo pode ser observado no Índice de Desenvolvimento Humano - IDH, divulgado anualmente pelo Programa das Nações Unidas para o Desenvolvimento PNUD. Isso não significa dizer que está tudo bem, mas serve para mostrar que a situação está melhor e que os caminhos percorridos pelas políticas públicas estão - ou estavam -, em grande medida, corretos. Na saúde, a mortalidade infantil caiu para 28,4 por mil nascidos vivos contra 39,6 em 1994 e na educação, em particular, avançamos muito. No início dos anos 90, de cada dez pessoas de 7 a 14 anos, duas estavam fora da escola; entre os pobres, um de cada quatro. E hoje são apenas 3\%, como na maioria dos países desenvolvidos. O represamento enorme de alunos no ensino fundamental deu lugar a um progressivo aumento da escolaridade - da ordem de $10 \%$ ao ano, o que significa muito, pois dobra o número daqueles que concluem o fundamental. Hoje, mais da metade da faixa etária consegue seu diploma deste nível inicial. O ensino médio, antes estagnado por falta de alunos, explodiu logo em seguida, pois passou a ser abastecido pelos diplomados do fundamental; de cerca de 2,5 milhões de alunos, passou a mais de dez milhões. A Coréia do Sul, por exemplo, mudou a imagem da educação do país, que, desde os anos 60 , investiu pesadamente na educação básica. Era um país mais pobre que o Brasil e hoje é muito mais rico, porque investiu nas pessoas. A educação é, portanto, decisiva na melhoria da qualidade de vida. Segundo Marcelo Néri, especialista em temas sociais, calcula-se que, para cada ano adicional de estudo, cresce cerca de $16 \%$ o salário mensal do trabalhador.

Não obstante, o compromisso mais premente de nossa sociedade é combater os altos índices de pobreza e indigência. Estudos do Instituto de Pesquisas Econômicas Aplicadas - Ipea, para 1998, indicam que o percentual de pobres na população brasileira declinou de $39 \%(62,5$ milhões) em 1977, para 33\% (50 milhões) em 1998, esta- bilizando-se, aparentemente, nesse patamar, excessivamente alto para um país com nosso padrão de desenvolvimento econômico.

Deve-se levar adiante ações que permitam iniciar um processo efetivo de distribuição de riqueza e inclusão social. Ao lado do investimento em educação, são necessários programas voltados para redistribuição de ativos produtivos aos mais pobres, buscando que eles sobrevivam numa economia de mercado e tenham capacidade de gerar sua própria renda; programas de transferência de renda, mas também de microcrédito para fomentar pequenos negócios, educação básica de qualidade, mas também capacitação para o trabalho e para a vida profissional por meio de aumento da oferta de educação técnico-profissional.

\section{UMA NOVA GERAÇÃO DE POLÍTICAS SOCIAIS DE COMBATE À POBREZA}

$\mathrm{Na}$ área social, a linha de ação do governo Lula é consolidar a unificação dos programas de transferência de renda criados pelo governo Fernando Henrique Cardoso - Bolsa-Escola, Bolsa-Alimentação, Cartão Alimentação - e do Fome Zero e o Vale-Gás. Sem dúvida, isso é um passo importante para efetividade das políticas de combate à pobreza, desde que mantidas as exigências de contrapartida tanto das prefeituras como dos beneficiários (crianças na escola, vacinação em dia, etc.) e ações complementares que promovam a emancipação das famílias.

Vale lembrar que a idéia não é nova, nem original. O Cadastro Único da Rede de Proteção Social começou a ser montado em setembro de 2001 e foi o instrumento utilizado para identificar os potenciais beneficiários de todos os programas da então chamada Rede de Proteção Social, concebido para formulação, acompanhamento e avaliação dos programas e ir além da transferência de renda.

Há alguns anos estão em implantação no Brasil programas de transferência de renda desenvolvidos pelos diversos níveis de governo, os quais foram iniciados em substituição progressiva da velha cesta básica por dinheiro direto às famílias, via cartões magnéticos e acesso ao sistema bancário, e se consolidaram na sociedade como uma nova forma de intervir na questão social. Pela primeira vez foi realizado um cadastro de pessoas realmente excluídas, além dos cadastros sociais existentes (Rais, FGTS, Previdência Social, PIS/Pasep, Previdência rural), 
o que permite que as famílias pobres e indigentes deixem de ser apenas um número estatístico e passem a ser identificadas pelos seus nomes e por outras informações importantes para os governos criarem programas eficazes e eficientes de redução da miséria e da vulnerabilidade social. Programas desse tipo são uma criação de prefeitos e governadores, conselhos e beneficiários, iniciativa privada e Terceiro Setor.

$\mathrm{O}$ cadastro deve ser o instrumento fundamental de sua implantação e, se bem gerenciado, é nele que encontramse as informações necessárias para intervenções sociais de todos os níveis de governo e da própria sociedade. Com ele, torna-se mais fácil não "errar o alvo" das políticas sociais, evita-se a pulverização de ações ao dar mais eficiência ao gasto social, além de dificultar o clientelismo e o partidarismo das políticas públicas.

Desde logo, é complexo identificar eticamente as pessoas realmente necessitadas em cada município brasileiro e há uma série de problemas envolvidos na gestão de um cadastro dessa natureza. Os beneficiários podem entrar ou sair da condição de pobreza conforme a variação de sua renda e inserção no mercado de trabalho; mudar de endereço ou de município; não cumprir contrapartidas exigidas pelos programas; nascerem e morrerem ou simplesmente desfazerem ou refazerem suas famílias - devido à crescente desestruturação do núcleo familiar, sobretudo nos grandes centros urbanos.

De toda forma, a gestão de políticas sociais com base em sistemas de informação e monitoramento é indispensável para promover maior efetividade destas políticas e dos gastos sociais.

\section{A ESTRATÉGIA DO GOVERNO DO ESTADO DE SÃO PAULO}

O governo do Estado quer promover a progressiva melhoria das condições de vida das famílias de baixa renda, especialmente as que habitam os bolsões de pobreza das regiões metropolitanas paulistas.

Essa camada da população é hoje alvo de diversos programas sociais nas três esferas de governo, porém com critérios diversos, o que gera a sobreposição de ações e a pulverização de recursos escassos e necessários. A inclusão social passa por maior racionalidade no gasto público e maior efetividade e integração de suas ações.

Como para o governo do Estado a pobreza não é apenas uma questão de insuficiência de renda, mas caracteriza-se pela dificuldade de acesso às políticas públicas, que ampliem as oportunidades das famílias pobres para superar as vulnerabilidades recorrentes, o governo de São Paulo está preparado para implantar ações complementares aos programas de transferência de renda para que estes não sejam meras compensações e sim efetivas alternativas de superação progressiva das condições de pobreza. Tratase de uma política de governo que envolve ações transversais e integradas em várias secretarias estaduais.

Dinamizar ações que melhorem a qualidade de vida das pessoas mais vulneráveis, que sinalizem uma perspectiva de futuro positiva e que as coloquem em condições de entrar de forma ativa no mercado de trabalho estão no programa do governo Geraldo Alckmin. Oportunidades por meio de frentes de trabalho e incentivo à lei do Aprendiz; educação profissional e capacitação para o trabalho; acesso a microcrédito e ampliação dos programas de transferência de renda; segurança alimentar por meio do programa do leite, Alimenta São Paulo, e restaurante Bom Prato e apoio à agricultura familiar serão integrados. Essas ações serão direcionadas às famílias em situação de pobreza localizadas nos setores censitários com maior concentração de vulnerabilidade social e econômica das regiões metropolitanas do Estado e em áreas sem dinamismo econômico. Em resumo, a pessoa que tiver o cartão magnético de acesso ao programa estadual de transferência de renda, o Renda Cidadã, ou o cartão do programa Bolsa Família do governo federal estará automaticamente credenciada para acesso a outros programas estaduais com vistas à sua emancipação dos programas de renda.

As organizações do governo têm em geral uma atuação fragmentada, muitas vezes com prioridades distintas ou até mesmo contraditórias. Para melhorar a gestão da área social e promover a integração e articulação de programas, são necessários instrumentos de gestão que coordenem as prioridades da agenda de governo. Por isso, o governo estadual criou o Comitê Gestor de Política Social, vinculado à Casa Civil, ${ }^{1}$ para coordenar as ações desenvolvidas por órgãos e secretarias.

O gerenciamento destas ações será feito por um cadastro social integrado. O Cadastro Pró-Social será o instrumento de comando dos programas sociais do Estado de São Paulo, georreferenciado em relação às áreas de maior concentração de pobreza e acoplado a um sistema de monitoramento e avaliação com recursos negociados com o BID e, além disso, estará integrado ao cadastro federal de programas de transferência de renda.

O desafio maior reside em criar "portas de saída" para a condição de miséria e desalento, pois certamente não 
construiremos um país mais justo se nos próximos anos incorporarmos crescentemente novas famílias a esse tipo de programa, o que acabaria criando mais pobres. Gerir formas eficazes de reduzir a pobreza e a desigualdade será uma prova de maturidade de toda sociedade brasileira daqui pra frente.

Há a necessidade de mecanismos de disseminação de informações que viabilizem o acesso ao conhecimento sistematizado, necessário para a tomada de decisões, bem como a avaliação e ações a partir de indicadores dos resultados e impactos das políticas e ações. A descentralização e o controle social são formas eficientes de gerir o gasto público. A proximidade com o usuário permite, com maior segurança, que as diversas esferas de governo participem da oferta de serviços, de acordo com as necessidades sociais do território, evitando desequilíbrios causados por desconhecimento da demanda.

Por isso é preciso que o processo de descentralização e municipalização da ação social seja irreversível. Nos municípios são maiores a possibilidade de uma verdadeira integração das políticas públicas e o efetivo controle por parte da sociedade - pré-requisitos para a construção de uma sociedade melhor e mais justa para os habitantes de São Paulo. O desenvolvimento social se realiza no plano local e requer a mobilização das comunidades. A descentralização de ações da área social, ocorrida com ênfase na segunda metade da década de 90, permitiu o fortalecimento do nível local para a tomada de decisões - e não apenas da aplicação dos recursos - e formulações de acordo com as necessidades mais precisas de cada localidade.

Em janeiro de 2004, o governo do Estado de São Paulo deu um passo inédito neste sentido, quando os diversos convênios com cada uma das prefeituras paulistas foram substituídos por um único convênio com cada município para financiar ações sociais locais para os grupos mais vulneráveis, definidas nos Planos Municipais de Assistência Social. O convênio único reduz a burocracia e custos processuais e propicia agilidade e flexibilidade administrativa tanto para o Estado, quanto para os municípios.

Assim, o governo estadual assume um papel estratégico na coordenação da política de desenvolvimento social de São Paulo: estabelecer objetivos e metas de apoio técnico às prefeituras e ao terceiro setor; e monitorar e avaliar as ações sociais desenvolvidas em todo o Estado por meio de um sistema de informações estratégicas - o PróSocial - que permita verificar regularmente o alcance, a efetividade e a correção das ações desenvolvidas.
Os planos de ação social devem ser elaborados levandose em conta algumas características regionais: há municípios onde a gravidade do problema social atinge mais as crianças e jovens e em outros, os idosos; a baixa escolaridade está mais presente na Baixada Santista e nas regiões de Registro e Franca; a violência juvenil assume proporções mais graves nas áreas metropolitanas; nas cidades pequenas, de baixo IDH, a questão central é renda, etc.

Para eficácia e eficiência na área social, é decisivo transferir o poder de decisão para quem estiver mais próximo do beneficiário; se de um lado, o governo do Estado transfere aos municípios o poder de formular os projetos que melhor atendam às necessidades específicas de seus grupos socialmente vulneráveis; de outro, reforça sua responsabilidade na execução direta de programas como o Renda Cidadã, de transferência de renda, com acompanhamento obrigatório às famílias atendidas.

\section{PARCERIAS COM A SOCIEDADE}

A diversidade de formas da pobreza e vulnerabilidade social requer uma flexibilidade na resposta que o setor público não tem. A dimensão da pobreza e da exclusão impõe uma coordenação de ações que as entidades privadas ou do Terceiro Setor não podem realizar. A parceria entre os dois é capaz de aumentar a eficiência das iniciativas que, ao atender aos mais pobres e vulneráveis, contribuam efetivamente para o desenvolvimento social.

Com esse objetivo foi criada a Rede Social São Paulo: integração e articulação de programas intersetoriais, evitando a fragmentação, a superposição e a pulverização das iniciativas e a busca de convergências e atuações conjuntas de diferentes áreas do governo, de organizações da sociedade civil e do empresariado paulista.

O papel da Secretaria Estadual de Assistência e Desenvolvimento Social é coordenar, estimular e apoiar a cooperação, animar as parcerias e articular as ações propostas. São membros da Rede Social: o governo do Estado de São Paulo, por meio de diversas secretarias, as entidades empresariais e suas fundações, os governos municipais, as organizações da sociedade civil que atuam no Estado de São Paulo, além dos conselhos de assistência social (acional, estadual e representantes dos municípios), Conselhos de Defesa dos Direitos da Criança e do Adolescente, Conselhos Tutelares e demais conselhos que atuam na área social.

Não se deve imaginar, contudo, que a integração e a coordenação de iniciativas restringem-se ao simples, ain- 
da que importante, objetivo da otimização de recursos. O objetivo maior é permitir aos atores intercambiar as experiências que desenvolvem e o conhecimento delas e de seus beneficiários. É esta troca que permitirá a todos no Estado de São Paulo implementar projetos que atendam cada vez melhor às necessidades da população mais carente, além de planos mais inovadores e efetivos, desenhados a partir de diagnóstico apurado da situação de pobreza no Estado.

\section{NOTA}

1. O comitê é formado pelas seguintes secretarias estaduais: Casa Civil, Assistência e Desenvolvimento Social, Trabalho e Emprego, Economia e Planejamento, Fazenda, Educação e Saúde.

\section{REFERÊNCIAS BIBLIOGRÁFICAS}

AFONSO, J.R. Brasil, um caso a parte. XVI Regional Seminar on Fiscal Policy. Cepal, Santiago, 2004.

ARRETCHE, M. Estado federativo e politicas sociais: determinantes da descentralização. São Paulo: Revan, 2000.

Brasil. Ministério da Educação. Fatos da Educação no Brasil: 19952002. Brasília, DF: MEC, 2000.

Políticas e Resultados 1995-2002: Relatórios de Gestão. Brasília, DF: MEC, 2002. 14 v.

CASTRO, M.H.G. de. Estratégia de adaptação do sistema de educação para atender à economia do conhecimento. Estudos e Pesquisas, Rio de Janeiro, n. 24, maio 2002. (Trabalho apresentado ao XIV Fórum Nacional do Instituto Nacional de Altos Estudos).

CASTRO, M.H.G de.; PRADO, I.; TIEZZI, S. Os desafios sociais no Brasil. Revista Conjuntura Democrática, Brasília, Fundação Astrojildo Pereira, 2004.
DRAIBE, S. Brasil, anos 90: as políticas sociais no marco das reformas estruturais. São Paulo: Unicamp/NEPP, 1999. (Relatório).

FRANCO, A. Três gerações de políticas sociais. Disponível em: $<$ http://www.e-agora.org.br/indice.php?cont=artigos\&id=60>. Acesso em 02 mar. 2004.

IBGE. Pesquisa Nacional de Amostragem por Domicílio 2002. Rio de Janeiro: IBGE, 2003.

Censo Demográfico 2000: síntese dos principais resultados. Rio de Janeiro: IBGE, 2002.

INEP. Censo da Educação Básica. Brasília: MEC, 2003.

OCDE. ORGANIZATION FOR ECONOMIC COOPERATION AND DEVELOPMENT. World Indicators Development. Paris: Edition, 2001.

SÃO PAULO (Estado). Relatório de Gestão 2003. São Paulo, Imesp, 2004.

Secretaria Estadual de Assistência e Desenvolvimento Social. Desenvolvimento Humano com compromisso e participação: diretrizes e programa de ação. São Paulo: Imesp, 2003.

Secretaria Estadual de Economia e Planejamento. Plano Plurianual 2003/2006. São Paulo: Imesp, 2002.

SCHWARTZMAN, S. Causas da pobreza. São Paulo: FGV, 2004.

SOUZA, P.R. Para um país mais igual, mais verbas para a educação. Estado de S.Paulo, São Paulo, 26 out. 2003, p. A-2.

Fome e analfabetismo. Estado de S.Paulo, São Paulo, 30 nov. 2003, p. A-2.

TIEZZI, S. O processo de descentralização brasileiro nos anos 90. 2001. 129 p. Dissertação (Mestrado em Políticas Públicas) - Universidade de Brasília (UnB), Brasília, 2001.

Maria Helena Guimarães de Castro: Socióloga, Secretária Estadual de Assistência e Desenvolvimento Social de São Paulo, Professora licenciada da Unicamp. Foi presidente do Instituto Nacional de Estudos e Pesquisas do Ministério da Educação no governo Fernando Henrique Cardoso (mhcastro@sp.gov.br). 